\title{
Heart Failure Due to Anomalous Pulmonary Vein Connection Associated with Atrial Septal Defect
}

\author{
Marcely Gimenes Bonatto, ${ }^{1 \text { (i) }}$ Ana Karyn Ehrenfried de Freitas, ${ }^{1 \text { (i) }}$ Letícia dos Santos de Oliveira Rocha, $^{2}$

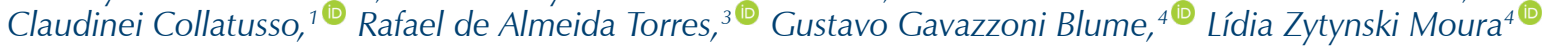 \\ Hospital Santa Casa de Curitiba, ${ }^{1}$ Curitiba, $P R$ - Brazil \\ Hospital Pequeno Príncipe, ${ }^{2}$ Curitiba, $P R$ - Brazil \\ Hospital Marcelino Champagnat, ${ }^{3}$ Curitiba, $P R$ - Brazil \\ Pontifícia Universidade Católica do Paraná, ${ }^{4}$ Curitiba, $P R$ - Brazil
}

\section{Introduction}

Anomalous pulmonary vein dreinage (APVD) is a rare disease, accounting for nearly 1 to $3 \%$ of congenital heart diseases. ${ }^{1}$ It may be total, when all PVs are involved, or partial, when only some PVs drain anomalously into one or more systemic veins or directly into the right atrium (RA). ${ }^{1,2}$ This condition occurs alone or in association with an interatrial septal defect, more often sinus venosus interatrial communication (IAC) (which accounts for nearly $5 \%$ of all IAC cases). ${ }^{3}$

Patients with this condition may remain asymptomatic until adulthood. However, overload of right chambers may trigger symptoms, especially reduced functional capacity and progressive dyspnea, in addition to the development of pulmonary hypertension $(\mathrm{PH})$ and ventricular dysfunction, which is the most severe disease scenario. ${ }^{3}$ Recognizing these symptoms and establishing early diagnosis and treatment is crucial to avoid disease progression and its prognostic implications.

We present a case of heart failure (HF) due to partial anomalous pulmonary vein dreinage (PAPVD) associated with IAC with reverse remodeling after surgical correction in adulthood.

\section{Clinical case}

A previously healthy 36-year-old patient was admitted to the emergency department with dyspnea that started nearly 15 days before and progressively worsened with time, evolving to dyspnea at rest, associated lower limb (LL) edema and orthopnea. On admission, the patient presented with tachydyspnea, blood pressure of 100x60 mm Hg, heart rate of $96 \mathrm{bpm}$, respiratory rate of $26 \mathrm{irpm}$, saturation of $93 \%$ on oxygen $4 \mathrm{~L} / \mathrm{min}$ via a nasal cannula. Examination revealed the presence of pathological jugular vein engorgement and

\section{Keywords}

Heart Failure/physiopathologyu; Darinage; Pulmonary Veins; Heart Septal Defects, Atrial; Heart Defects,Congenital; Cardiomegaly; Echocardiography/methods.

\footnotetext{
Mailing Address: Marcely Gimenes Bonatto •

Avenida Silva Jardim, 2939, apto 81, Água Verde. Postal Code 80240-020, Curitiba, PR - Brazil

E-mail: marcelybonatto@gmail.com

AManuscript received April 28, 2021, revised manuscript May 18, 2021 accepted June 11, 2021
}

hepatojugular reflux. Pulmonary auscultation showed crackles up to the bilateral middle third. Furthermore, we observed propulsive apex beat and palpable right ventricle (RV) by means of hooking palpation, with systolic murmur $3+/ 6+$ more evident in the left paraesternal region (accessory aortic focus) irradiating to the entire precordium, as well as rhythmic heart sounds with loud B2. Abdominal assessment revealed painful and palpable liver located $4 \mathrm{~cm}$ below the right costal margin, presence of bowel sounds, and no peritoneal signs. Finally, the patient presented with LL edema $3+/ 4+$.

Chest X-ray showed significant cardiomegaly, with increased apex beat and increased pulmonary artery trunk (PT), enlarged pulmonary hilum, and changes in vascular network, suggestive of congestion (Figure 1A). Electrocardiogram revealed sinus rhythm with right axis deviation, right bundle branch block, signs of biventricular and right atrium (RA) overload (Figure 1B). Laboratory tests did not show relevant changes.

Transthoracic echocardiogram showed PH (pulmonary artery systolic pressure [PASP] of $85 \mathrm{mmHg}$ ), major right chamber dilatation with RV dysfunction, left ventricle (LV) systolic dysfunction, grade 2 diastolic dysfunction, moderate pulmonary insufficiency, and major tricuspid insufficiency (Table 1). These findings were confirmed by transesophageal echocardiogram, which also revealed the presence of wide sinus venosus IAC, measuring $38 \mathrm{~mm}$ in its greatest diameter.

Chest computed tomography angiography (CTA) was requested to investigate the possible causes of $\mathrm{PH}$, showing cardiomegaly involving the right chambers, negative results for pulmonary thromboembolism but with signs of pulmonary artery hypertension (dilated PA trunk measuring $5.2 \mathrm{~cm}$ ) (Figure 1C).

On cardiac magnetic resonance, significant biventricular dilation and dysfunction (LV ejection fraction [EF] of 19\% and RVEF of 20\%) were found, as well as dilated RA and possible right inferior APVD for RA and PT dilatation (Figure 1D).

Initial clinical measures were taken to compensate the patient using intravenous diuretics and oral vasodilators. Subsequently, right heart catheterization was conducted, revealing wide sinus venosus IAC, right superior pulmonary vein with drainage in the superior vena cava, and right inferior pulmonary vein with drainage in the RA roof, RA oxymetric jump, HP (PASP $53 \mathrm{mmHg}$, pulmonary vascular resistance [PVR]: 3.04 woods), pulmonary-systemic flow ratio (Qp/Qs): 3.79/1, and PVR/systemic vascular resistance (SVR) 0,11.

The patient underwent surgical correction consisting of atrioseptoplasty with redirection of pulmonary vein blood flow, 


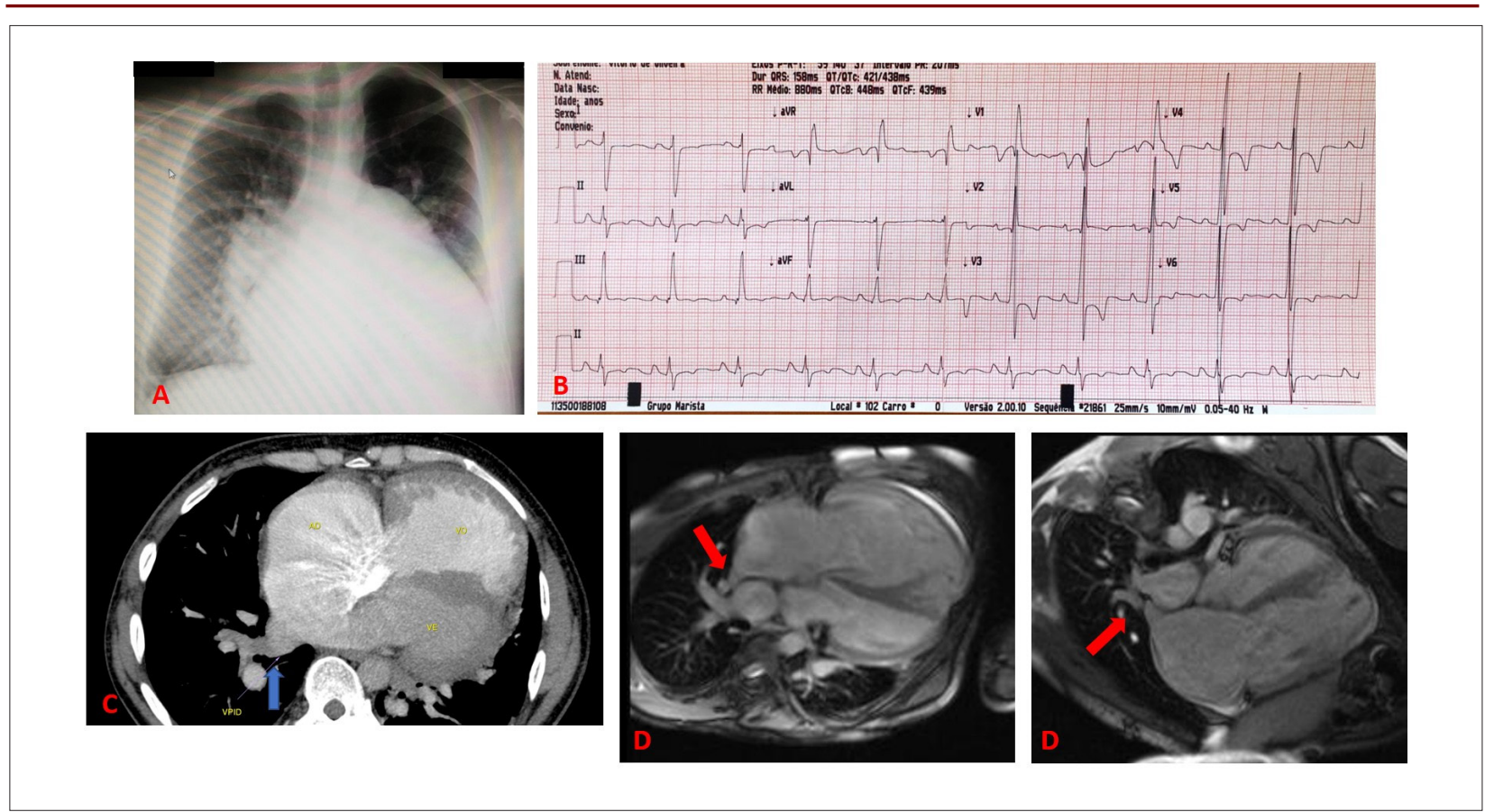

Figure 1 - Complementary tests. A: Chest X-ray. B: Electrocardiogram. C: Chest computed tomography angiography (blue arrow: entrance of the right pulmonary vein into the right atrium). D: Magnetic resonance imaging (red arrow: entrance of the pulmonary vein into the right atrium).

Table 1 - Evolution of echocardiographic and magnetic resonance findings before the procedure and 4 months and 1 year after treatment

\begin{tabular}{|c|c|c|c|c|}
\hline & $\begin{array}{l}\text { Magnetic resonance } \\
\text { imaging }\end{array}$ & Baseline echocardiogram & $\begin{array}{l}\text { Echocardiogram } 4 \text { months } \\
\text { after correction }\end{array}$ & $\begin{array}{c}\text { Echocardiogram } 1 \text { year after } \\
\text { correction }\end{array}$ \\
\hline Right atrium & Dilated & $143 \mathrm{~mL} / \mathrm{m}^{2}$ & Increased & $36 \mathrm{~mL} / \mathrm{m}^{2}$ \\
\hline Left atrium & $27 \mathrm{~mm}$ & $39 \mathrm{~mm}$ & $39 \mathrm{~mm}$ & $39 \mathrm{~mm}$ \\
\hline Left ventricle & $739 \times 591 \mathrm{~mL}$ & $46 \mathrm{~mm}$ & $42 \mathrm{~mm}$ & $44 \mathrm{~mm}$ \\
\hline RV functional assessment & EF $19 \%$ & FAC $25 \%$ & FAC $31 \%$ & FAC $24 \%$ \\
\hline Left ventricle & $178 \times 141 \mathrm{~mL}$ & $50 \times 44 \mathrm{~mm}$ & $50 \times 37 \mathrm{~mm}$ & $50 \times 36 \mathrm{~mm}$ \\
\hline LVEF & $20 \%$ & $26 \%$ & $51 \%$ & $54 \%$ \\
\hline Pulmonary insufficiency & Unvalued & Moderate & Moderate & Moderate \\
\hline Tricuspid insufficiency & Unvalued & Massive & Moderate & Mild to moderate \\
\hline Pulmonary trunk & $52 \mathrm{~mm}$ & $39 \mathrm{~mm}$ & $40 \mathrm{~mm}$ & $43 \mathrm{~mm}$ \\
\hline PASP & $\mathrm{ClA}$ & $85 \mathrm{mmHg}$ & $57 \mathrm{mmHg}$ & $46 \mathrm{mmHg}$ \\
\hline Other findings & $\begin{array}{l}\text { Possible right inferior } \\
\text { APVC to RA }\end{array}$ & IAC $38 \mathrm{~mm}$ & & \\
\hline
\end{tabular}

VD: ventrículo direito; FEVE: fração de ejeção do ventrículo esquerdo; PSAP: pressão sistólica da artéria pulmonar; FE: fração de ejeção; DAVP: drenagem anômala da veia pulmonar; $A D$ : átrio direito; $F A C$ : fração de alteração da área do ventrículo direito; CIA: comunicação interatrial.

with good evolution. He received hospital discharge and was prescribed with enalapril $5 \mathrm{mg}$ 12/12 h (maximum tolerated due to hypotension), bisoprolol $10 \mathrm{mg} / \mathrm{d}$, spironolactone $25 \mathrm{mg} / \mathrm{d}$, and furosemide $40 \mathrm{mg} / \mathrm{d}$. The patient returned to the outpatient clinic 4 months after the procedure, asymptomatic, with follow-up echocardiogram showing reverse remodeling (LVEF of $51 \%$ ) and moderate pulmonary and tricuspid insufficiency. These findings were maintained at late follow-up with a new echocardiogram 1 year after the procedure, with
LVEF of 54\%, moderate pulmonary insufficiency, and mild to moderate tricuspid insufficiency.

\section{Discussion}

PAPVD usually occurs during fetal development, secondary to failure of one or more pulmonary veins of right lung upper lobe in connecting to the left atrium. ${ }^{2,4}$ Physiologically, it produce a shunt from left to right, similar to an atrial septal 
defect, allowing for the already oxygenated blood to circulate again to the lungs, resulting in excessive pulmonary blood flow. In 80 to $90 \%$ of the cases, drainage occurs to the right and is associated with atrial septal defects, more commonly sinus-venosus IAC. 2,3,5

Many adults with PAPVD are accidentally diagnosed by chest images taken for any other indication, either with CTA in an emergency service to rule out pulmonary embolism, during cardiac catheterization for coronary intervention, or as part of an assessment of post-radiofrequency catheter ablation. ${ }^{6,7}$ Most patients with isolated PAPVD are asymptomatic. ${ }^{2,5,8}$ However, when this condition is associated with IAC, left-to-right (L-R) shunt occurs, which is responsible for increased right chamber flow and pressure leading to the remodeling of these chambers and of pulmonary vasculature and culminating in symptoms and in $\mathrm{PH} .{ }^{5,8}$ Since many patients remain asymptomatic up to adulthood, early diagnoses eventually occur as an incidental finding in less than $1 \%$ of the cases. ${ }^{2,5,8}$ In the remaining cases, diagnostic suspicion based symptoms directs the investigation.

The presence of IAC alone may not be responsible for the onset of symptoms. The magnitude and direction of flow depend on defect size and on the filling pressure of each ventricle. ${ }^{9}$ As a rule, the septal orifice needs to measure at least $10 \mathrm{~mm}$, have a Qp/Qs > 1.5/1.0, or promote right chamber dilatation in order to be considered a hemodinamically-significant L-R shunt. ${ }^{9}$

The main diagnostic test for PAPVD is transthoracic echocardiogram. ${ }^{3,5}$ However, in cases when this condition is associated with IAC, transesophageal echocardiogram, magnetic resonance imaging, or even right heart catheterization, may be required to elucidate the diagnosis. In addition to diagnosis, invasive hemodynamic assessment allows to calculate $\mathrm{Qp} / \mathrm{Q}$ ratio, an important information for therapeutic planning. ${ }^{2,3}$

The treatment of most PAPVD cases consists of clinical follow-up. ${ }^{2,3,8}$ Conversely, there is an increase in morbidity and mortality rates when cases of significant IAC do not receive early treatment. Patient's age and pulmonary pressures at the time of correction are the main outcome predictors. ${ }^{9,10}$ In both conditions, when there are symptoms, enlarged RV, or significant increase in L-R shunt $(\mathrm{Qp} / \mathrm{Q} s>1.5)$, surgical correction is mandatory and may be responsible not only of symptom resolution ${ }^{2,3,8}$ but also of reducing the likelihood of late arrhythmia, HF, and $\mathrm{PH}$ complications. The risk of arrhythmias increases after the age of 40 in non-operated patients, with atrial flutter, being more frequent up to the age of 60 years, and atrial fibrillation becomes predominant after this age. ${ }^{6,7}$

The short- and long-term results after surgical repair of PAPVD are excellent, and the reported complications rates are low. ${ }^{6,7}$ The association between reverse remodeling and improved clinical outcomes is well established in the literature. Therapies capable of promoting EF increase and reducing ventricle sizes are associated with lower mortality in HF. ${ }^{11}$
In the correction of heart diseases with L-R shunt, remodeling is expected after shunt surgical correction. The reduction in RA and ventricle volumes may occur as early as 24 hours after the procedure, but is generally more evident after 6 month and may extend to up to 18 months after the procedure. There is an expected reduction in right chambers, in tricuspid reflux, and in pulmonary pressures, as well as in improvement in LVEF, as observed in the present clinical case. However, the magnitude of remodeling is inversely proportional to patient's age at the time of closure, which reinforces the need for urgently starting treatment soon after symptom onset and diagnosis. ${ }^{9,12}$

Potential complications include stenosis or obstruction of pulmonary or systemic veins, residual IACs, or new atrial arrhythmias. ${ }^{6,7}$ Although rare, $\mathrm{PH}$ represents a special situation and, if present in an adult patient with PAPVC, may not undergo remission after repair. Advanced cases with RVP $>8$ woods or inversion of right-to-left shunt are contraindicated for surgical treatment. .,3,6-8 $^{-3}$

In the present report, the patient started to present with HF symptoms in adulthood, few days before admission. An etiologic investigation found APVD and IAC with important hemodynamic repercussion showing a significant increase in right chambers and in left-to-right shunt (Qp/Qs of 3.79), in addition to $\mathrm{PH}$ (PASP of $85 \mathrm{mmHg}$ ) and bilateral dysfunction. Surgical correction and pharmacological treatment of HF promoted clinical and echocardiographic improvement in an early and sustained fashion, reinforcing the importance of investigation and treatment of patients with this condition.

\section{Author Contributions}

Conception and design of the research: Bonatto MG; Acquisition of data, Analysis and interpretation of the data and Writing of the manuscript: Bonatto MG, Freitas AKE; Critical revision of the manuscript for intellectual content: Bonatto MG, Freitas AKE, Rocha LSO, Moura LAZ; Doctor responsible for the patient: Collatusso $C$; Assistance in imaging methods: Torres RA, Blume GG.

\section{Potential Conflict of Interest}

No potential conflict of interest relevant to this article was reported.

\section{Sources of Funding}

There were no external funding sources for this study.

\section{Study Association}

This study is not associated with any thesis or dissertation work.

\section{Ethics approval and consent to participate}

This article does not contain any studies with human participants or animals performed by any of the authors. 


\section{References}

1. Paladini D/ Pistorio A, Whu LH, Meccariello G Prenatal diagnosis of total and partial anomalous pulmonary venous connection: multicenter cohort study and meta-analysis. Ultrasound Obstet Gynecol. 2018; 52(1): 24-34.

2. El-Kersh K, Homsy E, Daniels CJ, Smith JS. Partial anomalous pulmonary venous return: A case series with management approach. Respir Med Case Rep. 2019; 27:100833.

3. Baumgartner H, De Backer J. 2020 ESC Guidelines for the management of adult congenital heart disease. Eur Heart J 2021; 42(6):563-645.

4. Paulista MD, Paulista ALP, et al. Tratamento cirúrgico da conexão anômala parcial das veias pulmonares em veia cava superior. Rev Bras Cir Cardiovasc. $2009 ; 24(2): 133-7$.

5. AboulHosn JA, Criley JM, Stringer WW. Partial anomalous pulmonary venous return: Case report and review of the literature. Cathet.CardiovasC Interv.; 58(4):548-52.

6. Alsoufi, S. Cai, G.S. VanArsdell, W.G. Williams, C.A. Caldarone, J.G. Coles: Outcomes after surgical treatment of children with partial anomalous pulmonary venous connection. Ann Thorac Surg.2007. 84:2020-6
7. Gatzoulis, Michael A., Webb, Gary D., Daubeney, Piers E. F. Diagnosis and management of adult congenital heart disease. Third edition. | Philadelphia, PA. Elsevier, [2018].

8. Pendela VS, Tan BE, Chowdhury M, Chow M. Partial Anomalous Pulmonary Venous Return Presenting in Adults: A Case Series With Review of Literature. Cureus. 2020;12(6):e8388.

9. Bhatt AB.. Congenital Heart Disease in the Older Adult. MAS on behalf of the American Heart Association Council on Clinical Cardiology. Circulation. 2015;131(21):1884-931

10. Le Gloan L, Legendre A, Iserin L, Ladouceur M. Pathophysiology and natural history of atrial septal defect. J Thorac Dis. 2018;10(Suppl 24):S2854-S2863. doi:10.21037/jtd.2018.02.80

11. Kramer DG, Trikalinos TA, Kent AJV, Konstam MA, Udelson, JE. Quantitative Evaluation of Drug or Device Effects on Ventricular Remodeling as Predictors of Therapeutic Effects on Mortality in Patients With Heart Failure and Reduced Ejection Fraction: a Meta-analytic Approach. J Am Coll Cardiol. 2010 July $27 ; 56(5): 392-406$.

12. Kumar P, Sarkar A, Kar SK. Assessment of ventricular function in patients of atrial septal defect by strain imaging before and after correction. Ann Card Anaesth. 2019;22(1):41-6. 